$12-2010$

\title{
Lymphocytic Hypophysitis
}

\author{
Saurabh Singhal \\ Harminder Singh MD \\ Thomas Jefferson University \\ Kevin Furlong \\ Lawrence C. Kenyon \\ James J. Evans \\ Thomas Jefferson University
}

Follow this and additional works at: https://jdc.jefferson.edu/jhnj

\section{Let us know how access to this document benefits you}

\section{Recommended Citation}

Singhal, Saurabh; Singh MD, Harminder; Furlong, Kevin; Kenyon, Lawrence C.; and Evans, James J. (2010) "Lymphocytic Hypophysitis," JHN Journal: Vol. 5 : Iss. 2 , Article 3.

DOI: https://doi.org/10.29046/JHNJ.005.2.003

Available at: https://jdc.jefferson.edu/jhnj/vol5/iss2/3

This Article is brought to you for free and open access by the Jefferson Digital Commons. The Jefferson Digital Commons is a service of Thomas Jefferson University's Center for Teaching and Learning (CTL). The Commons is a showcase for Jefferson books and journals, peer-reviewed scholarly publications, unique historical collections from the University archives, and teaching tools. The Jefferson Digital Commons allows researchers and interested readers anywhere in the world to learn about and keep up to date with Jefferson scholarship. This article has been accepted for inclusion in JHN Journal by an authorized administrator of the Jefferson Digital Commons. For more information, please contact: JeffersonDigitalCommons@jefferson.edu. 


\title{
Lymphocytic Hypophysitis
}

\author{
Saurabh Singhal, ${ }^{1}$ Harminder Singh, MD, ${ }^{2}$ Kevin J. Furlong, DO, ${ }^{3}$ \\ Lawrence C. Kenyon, MD, PhD, ${ }^{4}$ James J. Evans, MD ${ }^{2}$ \\ ${ }^{1}$ Visiting Medical Student, India \\ 2Department of Neurological Surgery, \\ ${ }^{3}$ Division of Endocrinology, Diabetes and Metabolic Diseases, \\ ${ }^{4}$ Department of Pathology, Anatomy and Cell Biology, \\ Thomas Jefferson University, Philadelphia, PA
}

\section{Case Presentation}

A 59 year-old female presented with visual problems in 2006, and was initially diagnosed with a pituitary macroadenoma on MRI (Figure 1). Preoperatively, the pituitary lesion decreased in size after the patient was started on steroids, raising the possibility of lymphoma and inflammatory conditions. Ultimately, endoscopic trans-nasal biopsy of the pituitary lesion revealed lymphocytic hypophysitis. She was treated with steroids for two years and developed several side effects from chronic steroid use, including Cushingoid features, diabetes, cataracts, weight-gain and osteopenia. As a result, she was subsequently treated with methotrexate and gradual weaning of the steroids.

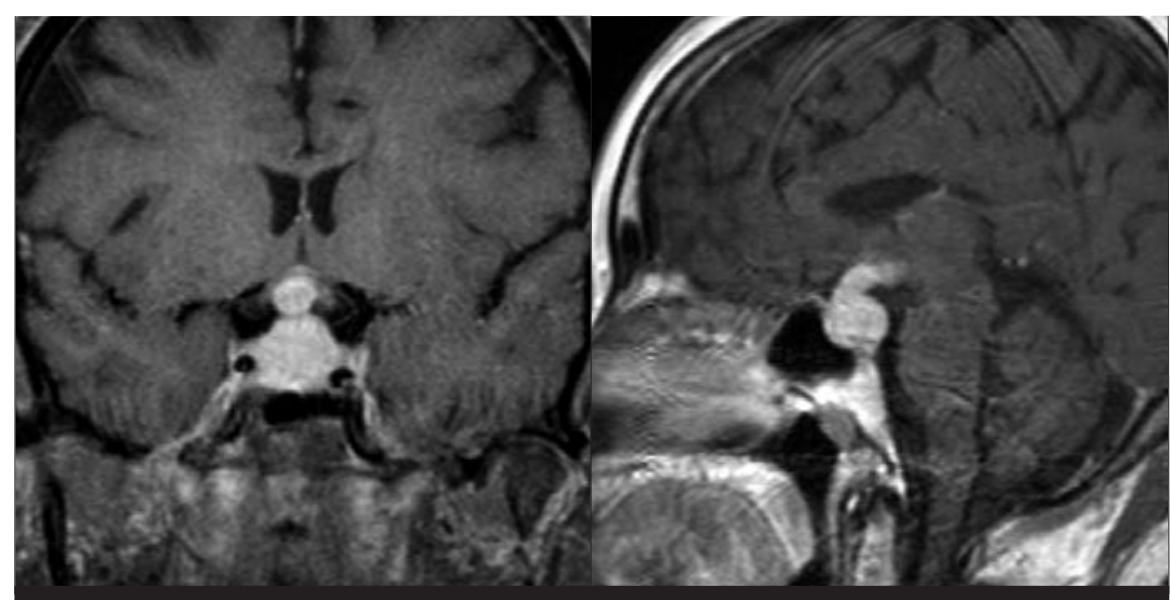

Figure 1

Pre-operative coronal and sagittal T1 post-contrast MRI. Note: suprasellar extension along infundibulum
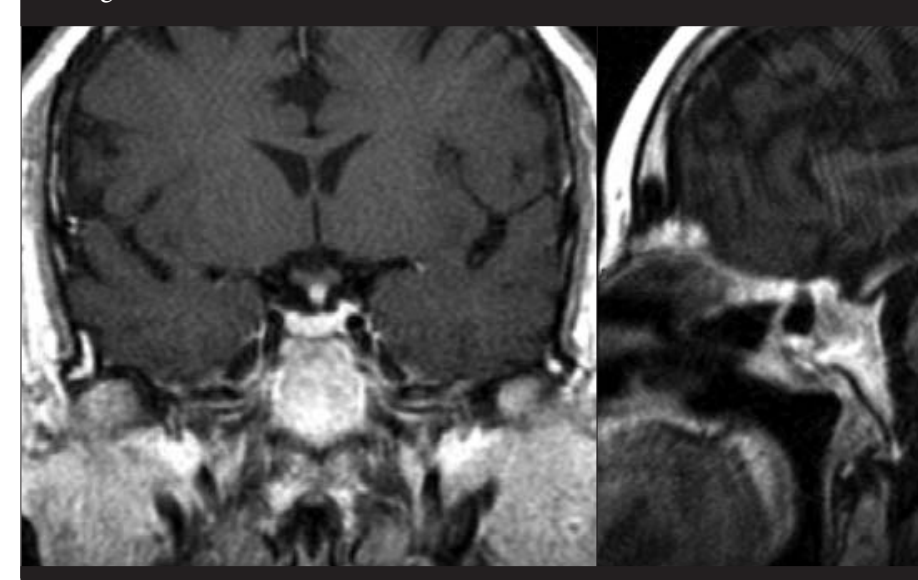

Figure 2

Most recent coronal and sagittal T1 post-contrast MRI with patient on methotrexate treatment.
The latest MRI of the brain (Figure 2) revealed some thickening and enhancement within the sella and along the infundibulum. Overall the volume and degree of enhancement appeared unchanged compared to MRI's over the past two years and seems to have reached a steadystate on her current medication regimen. The patient is maintained on methotrexate $15 \mathrm{mg}$ weekly and prednisone $5 \mathrm{mg}$ daily for baseline hypocortisolemia. She states that she has been feeling well, has normalized vision, and reports an improvement in side-effects, including weight loss, less Cushingoid features, and better glycemic control.

We anticipate long-term management on the current regimen of methotrexate and prednisone as she has had several serial MRI scans and ophthalmology examinations that have remained stable. Annual MRI scans will be obtained, and will be performed sooner if she develops symptoms of worsening disease or there is a change in the dose of methotrexate.

\section{What is this disease?}

Lymphocytic hypophysitis (LH) is an uncommon autoimmune disease in which the pituitary gland is infiltrated by lymphocytes, plasma cells and macrophages and its function is usually impaired. ${ }^{1}$ It was first described 2 by Goudie and Pinkerton in 1962. Its annual incidence has been estimated at one case per 9 million and data from most series show that it is present in less than $1 \%$ of all surgical specimens. ${ }^{2}$ This may be an underestimate since the frequency of case reports has increased in recent years. It has been most commonly described in post-partum women, but can occur outside this scenario. Some patients may also exhibit an autoimmune poly-endocrinopathy.

\section{Classification and Pathology}

Anterior hypophysitis is the most common form, confined to the adenohypophysis. It causes adenohypophyseal destruction and hypopituitarism. Diabetes insipidus (DI) is uncommon.

Infundibular and posterior hypophysitis is much less common, causing diabetes insipidus and hyperprolactinemia from pituitary stalk dysfunction. This involves the neurohypophysis and pituitary stalk. The anterior pituitary is usually preserved.

Lymphocytic infundibular panhypophysitis is a much rarer form with lymphocytic infiltration and destruction in both the anterior and the posterior parts of the pituitary gland. These 


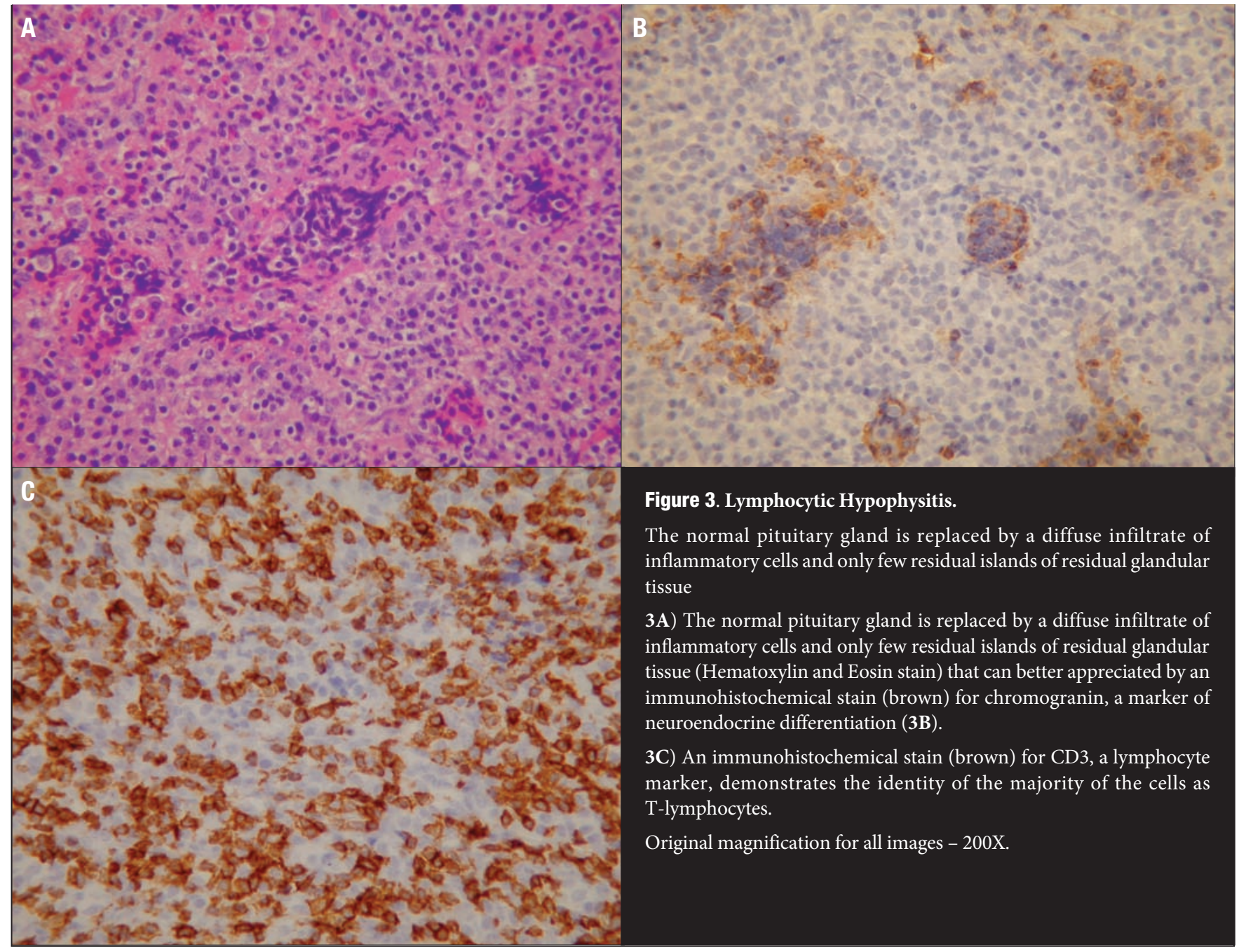

patients develop pan-hypopituitarism and present with a combination of DI and anterior pituitary dysfunction.

\section{Pathogenesis}

The disease is characterized by autoimmune pathogenesis with focal or diffuse inflammatory infiltration (Figure 3 ) and varying degrees of pituitary gland destruction. It typically follows a course in which the pituitary gland initially increases in size simulating a mass, later followed by shrinkage due to fibrotic changes. ${ }^{4,5}$ Hypopituitarism with empty sella syndrome is a common final outcome when the inflammation resolves.

\section{Clinical Findings}

Symptoms include headaches, watery nasal drainage, facial pain, skin changes, dizziness, constipation, diarrhea, temperature intolerance, body hair loss, increased fatigue, seizures, weight gain or loss, sexual disorders and loss of libido, low blood pressure, visual disturbance and often bitemporal visual field loss secondary to chiasmal compression when there is an inflammatory mass effect. Other symptoms include anterior pituitary hypofunction (63\%), diabetes insipidus (19\%), hyperprolactinemia (38\%), and autoimmune thyroditis (25\%). ${ }^{6}$

\section{Diagnosis and Investigations}

A presumptive clinical diagnosis can be made if there is a history of gestational or postpartum hypopituitarism, a contrast-enhancing sellar mass with imaging features characteristic of lymphocytic hypophysitis, and a pattern of pituitary hormone deficiency with early loss of adrenocorticotrophic hormone (ACTH) and thyroid-stimulating hormone (TSH). This is in contrast to the hormone loss pattern typically found with macroadenomas (i.e., sequential loss of growth hormone, luteinizing hormone/ follicle-stimulating hormone, and later ACTH, and TSH).
Biopsy is the only accurate means of diagnosis. Other investigations include MRI, clinical endocrinological assessment, CSF examination for lymphocytosis, elevated protein, and increased serum thyroglobulin antibody concentration.

Biopsy is the only accurate means of diagnosis. Other investigations include MRI, clinical endocrinological assessment, CSF examination for lymphocytosis and elevated protein, and serum thyroglobulin antibody concentration.

\section{Imaging}

Radiological findings include an enlarged pituitary gland and suprasellar extension is common with possible involvement of the pituitary stalk. Radiographically, it can be differentiated from pituitary adenoma as shown in the table. ${ }^{7-10}$

Lymphocytic hypophysitis can be confused with macroadenoma as mentioned above, and also with gestational hypopituitarism, 
Table

\begin{tabular}{|l|l|}
\hline Lymphocytic Hypophysitis & Pituitary Adenoma \\
\hline Gland symmetrically enlarged & Asymmetrically enlarged \\
\hline Administration of gadolinium homogenously enhances the gland & Often differential enhancement of the tumor and the pituitary gland \\
\hline Hypointense on T1 and high signal on T2 weighted images & Isointense on both T1 and T2 images \\
\hline Unique contrast enhancement may involve adjacent dura mater and infundibulum & Contrast enhancement, sellar and suprasellar, with expanded sella \\
\hline
\end{tabular}

Sheehan syndrome, lymphoma, tuberculosis, sarcoidosis, or syphilis. ${ }^{11}$ There has been a case of suprasellar germinoma masquerading as lymphocytic hypophysitis ${ }^{12}$ and a case reported with lymphocytic hypophysitis and thyroiditis associated with aseptic meningitis where a viral illness was proposed to be the etiological cause. ${ }^{13}$

\section{Management}

Appropriate management remains controversial due to limited clinical case studies owing to the rarity of this disease.

Corticosteroid therapy has been advocated as a means of attenuating inflammation, but given the uncertainty of its efficacy and the known adverse effects, such therapy does not seem justified for most patients. Other immunosuppressants, such as methotrexate or cytoxan, offer the anti-inflammatory benefits of corticosteroids without the negative side-effects of long-term steroid use.

The role of surgery is mainly for tissue diagnosis and is sometimes also indicated for decompression of surrounding structures. ${ }^{7}$ Surgical decompression is indicated in the presence of symptomatic optic chiasm compression, in the face of ineffective steroid therapy, or the impossibility of establishing the diagnosis with sufficient certainty by less invasive means. ${ }^{11}$ Gamma Knife surgery has been utilized ${ }^{14}$ for persistent refractory disease.

All patients with lymphocytic hypophysitis require close observation for pituitary hormonal hyposecretion and appropriate hormone replacement therapy. Long-term follow-up is mandatory to monitor for the development of other delayed hormonal deficits. Patients with a presumed diagnosis of lymphocytic hypophysitis should be observed closely and undergo serial visual field examinations, endocrine evaluation with blood work, and serial imaging studies until they are in remission.

\section{References}

1. Bellastella A, Bizzarro A, Coronella C, Bellastella G, Sinisi AA, De Bellis A. Lymphocytic hypophysitis: a rare or underestimated disease? Eur J Endocrinol. 2003;149:363-376.

2. Goudie RB, Pinkerton PH. Anterior hypophysitis and Hashimoto's disease in a young woman. J Pathol Bacteriol. 1962;83:584-585.

3. Caturegli P, Newschaffer C, Olivi A, Pomper MG, Burger PC, Rose NR. Autoimmune hypophysitis. Endocr Rev. 2005; 26:599-614.

4. Carpinteri R, Patelli I, Casanueva FF, Giustina A. Inflammatory and granulomatous expansive lesions of the pituitary. Best Pract Res Clin Endocrinol Metab. 2009; 23(5):639- 650.

5. Karaca Z, Tanriverdi F, Unluhizarci K, Kelestimur F, Donmez H. Endocr Res. 2009; 34(1-2):10-17.
6. Thodou E, Asa SL, Kontogeorgos G, Kovacs K, Horvath E, Ezzat S. Clinical case seminar: lymphocytic hypophysitis: clinicopathological findings. 1995; J Clin Endocrinol Metab 80: 2302-2311.

7. Molitch ME, Gillam MP. Lymphocytic hypophysitis. Horm Res. 2007; vol. 68, suppl. 5, 145-150.

8. Stromberg S, Crock P, Lernmark A, Hulting AL. Pituitary autoantibodies in patients with hypopituitarism and their relatives. J Endocrinol. 1988; 157 (3): 475-480.

9. Pressman EK, Zeidman SM, Reddy UM, Epstein JI, Brem H. Differentiating lymphocytic adenohypophysitis from pituitary adenoma in the peripartum patient. J Reprod Med. 1995;40:251-259.

10. Saiwai S, Inoue Y, Ishihara T, Matsumoto S, Nemoto Y, Tashiro T, Hakuba A, Miyamoto T: Lymphocytic adenohypophysitis: skull radiographs and MRI. Neuroradiology. 1998;40:114-120

11. Kristof RA, Van Roost D, Dietrich Klingmüller D, Wolfram Springer W, Schramm J. Lymphocytic hypophysitis: non-invasive diagnosis and treatment by high dose methylprednisolone pulse therapy? J Neurol Neurosurg Psychiatry. 1999;67:398-402.

12. Nishiuchi T, Imachi H, Mura K, Fujiwara M, Sato M, Nishiuchi Y, Kushida Y, Haba R, Atsushi T, Takashi T, Ishida T. Suprasellar germinoma masquerading as lymphocytic hypophysitis associated with central diabetes insipidus, delayed sexual development, and subsequent hypopituitarism. American Journal of the Medical Sciences. 2010; 339(2):195-199.

13. Lim S, Elston MS, Swarbrick MJ, Conaglen JV. Lymphocytic hypophysitis with associated thyroiditis in a man with aseptic meningitis. Pituitary. 2009; 12(4):375-379.

14. Ray DK, Yen CP, Vance ML, Laws ER, Lopes B, Sheehan JP. Gamma Knife surgery for lymphocytic hypophysitis. Journal of Neurosurgery. 2010; 112(1):118-121.

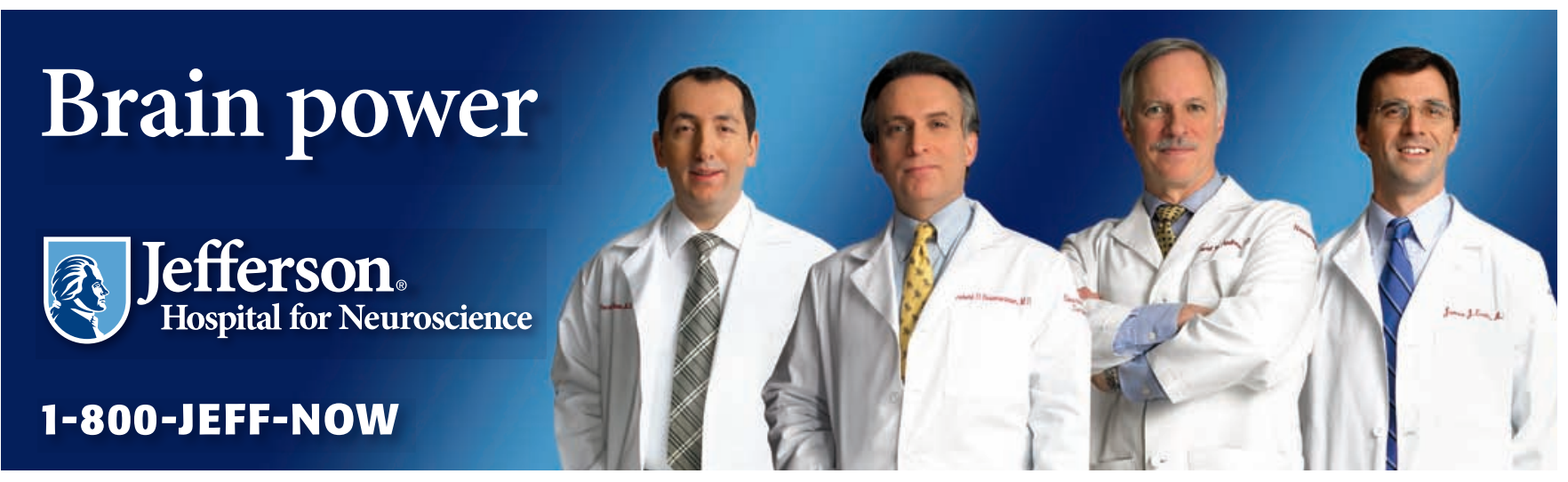

